\title{
Resilience of the Russian financial system under external shocks
}

\author{
Irina Korostelkina*, Elena Dedkova, and Natalia Varaksa \\ Orel State University, Naugorskoe highway, 40, 302020 Orel, Russia
}

\begin{abstract}
The situation in the world financial market has formed under the influence of various challenges and threats, most of which could be predicted, or at least remotely forecasted. At the same time, the ubiquitous spread of COVID-19 and the extremely adverse negative consequences of the pandemic came as a real shock to the global and domestic financial systems. The article examines the factors and principles of the resilience of the Russian financial system, identifies the reasons for the emergence of global and internal economic crises, discloses government measures to maintain global financial resilience, and analyzes the set of measures taken by the Government of the Russian Federation to support the economy and financial system in the context of the COVID-19 pandemic. The objective of the research is to consider the factors of resilience of the Russian financial system under external shocks and to assess the measures taken by financial regulators in connection with the COVID-19 pandemic to ensure the growth of the global financial system. General and specific research methods, methods and tools of graphic interpretation, comparative analysis, and accompanying changes are used as methodological tools for this study.
\end{abstract}

\section{Introduction}

The world economies and financial systems have previously experienced stagnation and regression caused by the consequences of global viral infections. However, the current situation and unfavorable forecasts of relapses in mass population infection (new and repeated cases) force states to take serious measures in the political, social, economic, financial, and other spheres. The processes of globalization and integration within the framework of the world financial system have caused the development of the sensitivity of national economies to dynamic changes in world markets (in particular, for commodity exporters such as the Russian Federation) [1].

Changes in the global political and socio-economic situation significantly affect international capital flows and exchange rates of national currencies. An increase in the qualitative and quantitative characteristics of systemic financial risk at the global level has an extremely negative impact on the key macroeconomic indicators of the Russian economy. Also, the domestic financial system is exposed to (asymmetric, uneven, and multidirectional) a variety of factors that affect, either directly or indirectly, its resilience

*Corresponding author: cakyra_04@mail.ru 
[1]. A number of these factors are cyclical and caused by the patterns of development of the domestic and world financial system (structural crises of the economy, political events, demographic and social situation, etc.), while others are extraordinary (spread of a pandemic, man-made disasters, natural disasters).

The article deals with the study of the resilience of the Russian financial system. The modern economy gives rise to new challenges and threats. Scientists and economists around the world are trying to solve the problem of ensuring financial resilience by creating an optimal set of tools. Therefore, this study is essential and necessary at the present stage of economic development.

\section{Materials and Methods}

In the preparation of this study, the authors used general scientific methods, such as the method of comparison, analysis, and generalization. Besides, the research results were obtained using private scientific methods. During the study, the tools of graphic interpretation, comparative analysis, and the method of accompanying changes were used. The concept of financial resilience and the principles of the functioning of the financial system were determined using a comparative approach. The factors affecting the resilience of the financial system of the Russian Federation are disclosed using the graphical method. Changes in the S\&P 500 stock index and its volatility were determined using technical analysis. The systematization of measures and tools to ensure the resilience of the financial system of the state was carried out using the methods of scientific research, such as literature review, hypothesis building, and expert assessment.

\section{Results and Discussion}

The main criterion for the economic security of the state is its resilient financial system, which quickly responds to modification processes in the economy at the international and national levels, which determines the strongest influence on its state of international and local crises (shocks). The instability has an extremely negative effect on financial processes, leading to inflation, exchange rate surges, and an increase in the number of debt obligations [2].

Both domestic and foreign scientists have considered the issues of financial resilience, the resilience of the financial system of states. In particular, M.S. Podkuiko [3] considered the world level of financial resilience during periods of various economic crises. Ensuring financial resilience as a new state function was studied by M.M. Kovalev, S.I. Paseko [4]. In particular, the mechanisms and instruments of macroprudential regulation were analyzed to ensure financial resilience, and alternative models of macro-regulators were studied. A.N. Sukharev [5] and A.S. Gromova [6] considered financial resilience as a factor in the development of national security. The works by L.M. Shevchenko present the best world practices in the study of financial resilience [7].

Foreign scientists have also assessed the impact of systemic risks on the financial system. Bratis T., Laopodis N.T., and Kouretas G.P. investigated the problems of financial resilience during the eurozone debt crisis [14]. Jin X., Nadal De Simone F. assessed the impact of traditional and non-traditional shocks of monetary and macroprudential policy in the eurozone [15].

Research by scientists on ensuring the security of financial markets seems to be interesting from a practical and theoretical point of view. E.A. Loktionova [8] proposes an algorithm for assessing the security level of the financial market, substantiates the need for 
continuous monitoring of the structural components of the financial market under stressful situations, strategic challenges, and security threats.

An essential prerequisite for macroeconomic resilience is the maintenance of the financial system resilience. This goal should be recorded in the substantive part of the basic principles of the financial system:

- buoyancy, flexibility, and adequacy to the state of development of economic relations in the country and the conditions of globalization;

- creation of the conditions for the coordinated and synchronous functioning of all elements and areas of the financial system;

- adequate funding of the financial system infrastructure;

- transparency, which implies open access to informative data on the operation of the financial system.

The resilience of the Russian financial system depends on external and internal factors (Fig. 1).

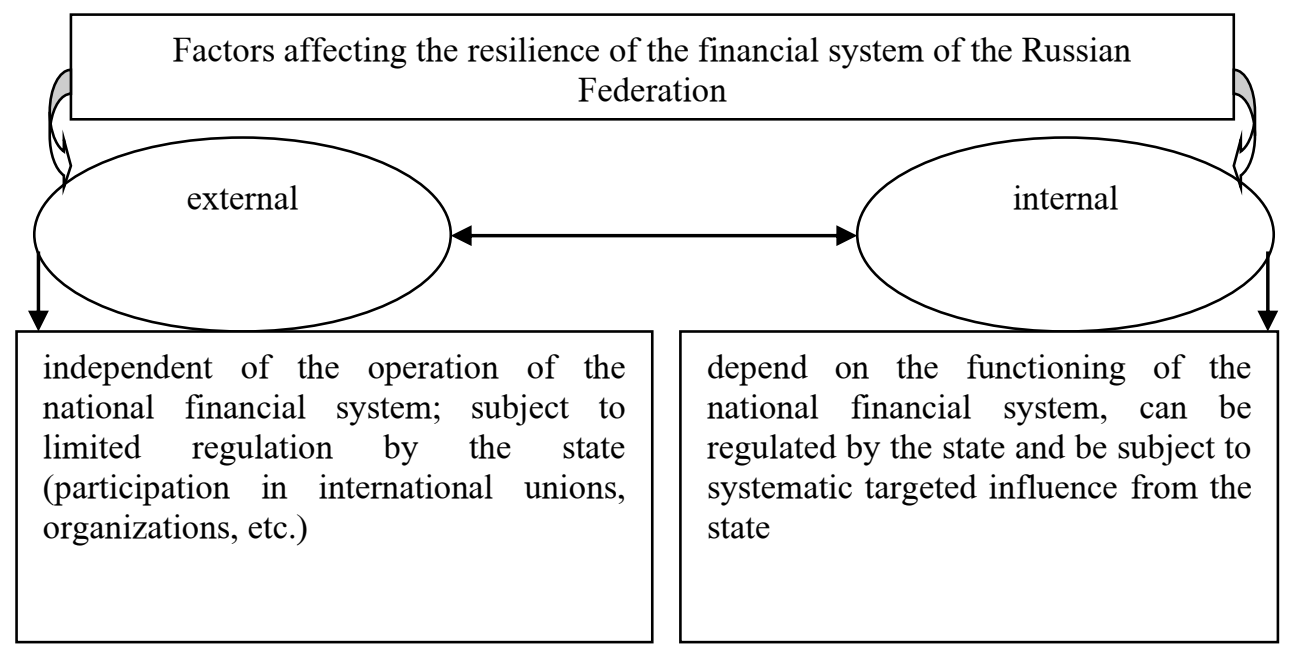

Fig. 1. Factors affecting the resilience of the financial system of the Russian Federation

The combination of external and internal factors in interrelation and interdependence is critical for the resilience and progressive development of the financial system of the Russian Federation. At the same time, there are other, more detailed, classifications of factors that determine the state of the financial system for various reasons. In particular, L.M. Shevchenko in her classification distinguishes political, economic, social, organizational and managerial, legal, geographic, technological, and infrastructural factors [9]. Considering these factors will further help more quickly respond to relatively predictable and impossible to identify in terms of occurrence risks and threats to the resilience of the financial system.

At the same time, the risks and threats, although they are often unpredictable, have quite expected consequences, while external shocks often have a detrimental effect on the resilience of the financial system, as they are lightning-fast and unprecedented. External shocks lead to changes both in the main macroeconomic indicators (GDP, inflation, exchange rates, etc.) and in the resilience indicators of the national financial system (budget surplus, level, and dynamics of prices, the amount of external and internal debt of the state, the volume of the gold and foreign exchange fund, investment attractiveness of the country's economy, etc. [2]).

Academic economists note that the world financial crisis of 2007-2009 significantly 
intensified the role of external shocks in the sustainable development of financial systems of states. The state of the world financial system came to the fore in comparison with the peculiarities of national financial systems. In particular, this was especially acutely reflected in the exchange rates and the inflow of foreign investment.

In addition to the global financial crisis, the Russian financial system was shocked by the consequences of the political and economic sanctions of 2014 (many of which are prolonged, extended, and currently in force). The practice of applying sanctions, implemented by a state (a coalition of countries) to influence other countries through the use of indirect methods of influence, has been widely used for hundreds of years. The last open sanctions (political, economic, and social) were imposed on Russia by other countries (USA, Western Europe) when our country was part of the USSR. The accession of the Crimean peninsula to the Russian Federation and the conflict in the eastern part of Ukraine led to new anti-Russian sanctions (restrictive political and economic measures), the consequences of which were an increase in credit rates; restricted access for certain Russian banks, and companies to international banking products; the outflow of foreign investment [10], which shocked the domestic financial system and required the development of urgent measures to neutralize the negative impact on the domestic economy. Despite the complex of measures taken at the state level, the long-term effect of the sanctions led to an outflow of foreign capital; increasing tax rates for several taxes (VAT, excise taxes), and the introduction of new taxes (tax on additional income from the extraction of hydrocarbons), raising the retirement age, aggravating the consequences of the 2020 financial crisis (rising inflation and ruble's decline), drop in oil prices, etc.

At the same time, we can talk about the positive consequences of anti-Russian sanctions. The most significant of them are deepening and expanding ties with countries promising partners (in particular, with China), development and widespread implementation of Mir national payment system; transition to settlements for international transactions in national currency, reorientation of the Russian economy to priority sectors from raw materials segments to segments with high added value; development of import substitution policy.

Thus, we can talk both about the extremely unfavorable consequences of external shocks for the domestic financial system and about the fact that the crisis-stress situation gives an impetus to the activation of underdeveloped, but promising instruments, links, and spheres of the financial system of the Russian Federation, aimed at ensuring the resilience and progressive development. There is a dynamic decrease in the dependence of the Russian financial system on other countries - world leaders. The anti-Russian sanctions have intensified the development of import substitution, which is the main economic mechanism for increasing Russia's GDP and successfully restoring economic processes and stabilizing the financial system.

The consequences of the widespread COVID-19 pandemic, which exacerbated stress on the hydrocarbon market, sanctions restrictions and led to the closure of international borders and a large number of people staying out of work for an indefinite period, became unexpected, and therefore the most difficult in terms of regulation and management of an external shock for the domestic financial system.

The whole world has realized that the COVID-19 pandemic caused an unprecedented crisis in human resources and health [11]. Comprehensive containment measures (requiring significant financial resources) triggered an economic downturn. The situation is aggravated by uncertainty about its depth and duration. The financial system has been hit hard (prices of risky assets have fallen sharply, while borrowing costs have risen significantly; emerging market and border economies have experienced the sharpest reversal in portfolio capital flows) and further exacerbation of the crisis could affect global financial resilience. Since the outbreak of the pandemic, prices for risky assets have sharply 
dropped. As an example, we provide the S\&P 500 stock index, which includes 505 US public companies with the largest capitalization (Fig. 2).

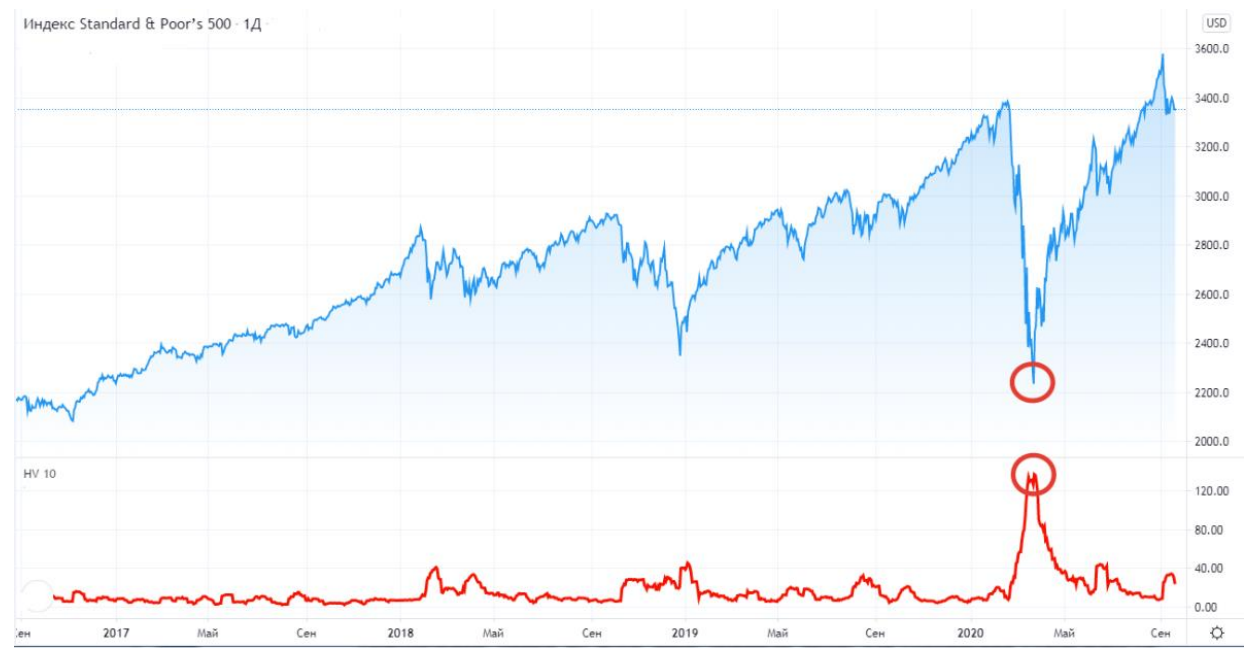

Fig. 2. Changes in the S\&P 500 stock index and its volatility

Under uncertainty about the economic impact of the pandemic, there is a surge in volatility (the lower curve is shown in the graph), which has led to a significant decrease in liquidity in markets, including in markets that are traditionally viewed as capacious, which contributed to sharp surges in asset prices.

Central banks around the world have taken steps to maintain the resilience of the global financial system and support the global economy: liberalize monetary policy by lowering policy rates; adjusting the future trajectory of monetary policy in terms of the current environment and expanding asset purchase programs; they have provided additional liquidity to the financial system, negotiated the provision of USD liquidity through credit line swap facilities, revived programs used during the global financial crisis, and launched several new large-scale programs, including for the purchase of riskier assets ( corporate bonds). The volumes of state support measures by country are shown in Fig. 3.

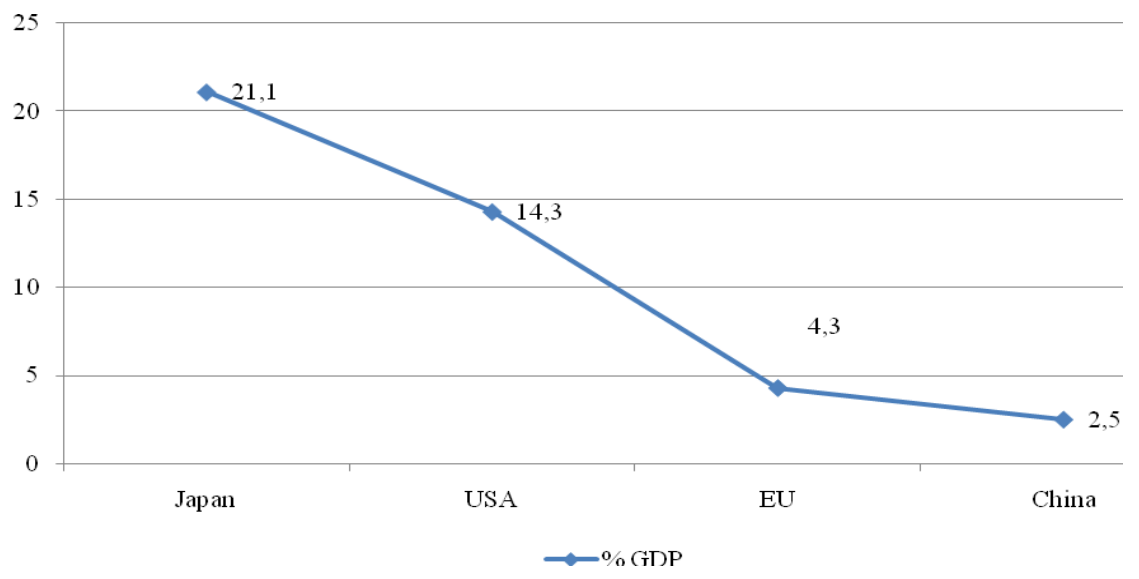

Fig. 3. Volumes of state support measures by country (based on data from [12])

As a result of these actions, aimed at containing the pandemic-induced recession, 
tensions in some markets have slightly eased, and prices of risky assets have recovered. However, sentiment remains volatile, and global financial conditions remain much tighter than in early 2020.

The drastic tightening of global financial conditions since the start of the COVID-19 outbreak in the not-too-distant future is expected to pose significant downside risks to economic growth and financial resilience. Currently, there is a probability of about $5 \%$ (a situation that occurs once every twenty years) that global growth will decline to below $7.4 \%$. For comparison, in October 2019, this threshold was more than 2.6\% [11]. The COVID-19 pandemic has had a significant negative impact on economic activity, with global growth projected at $5.4 \%$ in 2021 . The same forecast indicates a possible decrease in Russia's GDP by $6.6 \%$ in 2020 [13].

The global spread of COVID-19 may require tighter and longer-lasting containment measures that could further tighten global financial conditions if they cause a deeper and longer economic downturn. This tightening may, in turn, expose the financial vulnerabilities that have accumulated over recent years in an environment of extremely low interest rates. This will further exacerbate the shock created by COVID-19. Central banks will continue to play an important role in maintaining the resilience of global financial markets and the flow of credits to the economy. At the same time, the joint implementation of monetary, fiscal, and financial policies should be challenged to mitigate the impact of the shock caused by COVID-19 and ensure a stable and sustained recovery when the pandemic is brought under control. Close and continuous coordination at the international level will be critical to maintaining countries' vulnerability, restoring market confidence, and containing risks to financial resilience.

In Russia, the measures developed by the government to support the economy and financial system in the context of the COVID-19 pandemic, consisting of the support to the population (providing necessities, supporting employment, importing necessary goods); support for the most vulnerable sectors of the economy (tax incentives, exemptions, the establishment of compensation); support for small and medium-sized businesses (deferral of inspections, preferential loans); support for the financial system (creation of reserve and guarantee funds, measures to support the domestic currency, to prevent capital outflow from the country), etc., even though have taken effect, but are insufficient [13]. The current economic situation in Russia requires a significant concentration on ensuring sustainable economic growth.

\section{Conclusion}

Integration into the global economic space requires Russia to constantly monitor its financial resilience to promptly respond to changes in its state. According to the main macroeconomic indicators, the financial resilience of Russia has rather high values (in comparison with developed countries), while at the meso- and micro-levels the situation is negative. The underdevelopment of financial institutions and the financial market (dependence on foreign investment), the backwardness of the Russian banking system from the global average level, instability of the country's stock market (volatility of financial instruments, low investment attractiveness, low financial literacy of the population) are among the most pressing problems of the development of the domestic financial system. In light of the identified problems, the appropriate elimination measures must be developed, as well as ways to develop the internal investment market must be found. 


\section{References}

1. M.G. Tiunova, Finances: theory and practice, 22, 146 (2018)

2. Resilience of the Russian financial system, https://spravochnick.ru/

3. M.S. Podkuiko, Financial research, 15 (2007)

4. M.M. Kovalev, S.I. Paseko, Management problems, 1, 20 (2013)

5. A.N. Sukharev, Economic analysis: theory and practice, 31, 8 (2010)

6. A.S. Gromova, Bulletin of Tomsk State University, 1, 154 (2012)

7. L.M. Shevchenko, Financial analytics: challenges and solutions, 35, 48 (2014)

8. E.A. Loktionova, Finance and credit, 6, 1469 (2018)

9. L.M. Shevchenko, Bulletin of Saratov State Social and Economic University, 2, 101 (2013)

10. O.Iu. Sergeeva, A.A. Karimova, Issues of economics and management, 1, 134 (2017)

11. T. Adrian, F. Natalucci, The COVID-19 Crisis Threatens Financial Resilience, https://www.imf.org/

12. Information and analytical material of the Bank of Russia - Financial Resilience Review, https://cbr.ru/

13. Global Financial Resilience Report, https://www.imf.org/ru/

14. T. Bratis, N.T. Laopodisb, G.P. Kouretas, Journal of Financial Resilience, 47 (2020)

15. X. Jin, F. Nadal De Simone, Journal of Financial Resilience, 49 (2020) 